\title{
The Association of Cortisol Excretion with Weight and Metabolic Parameters in Nondiabetic Patients with Morbid Obesity
}

\author{
Johanna Maria Brix ${ }^{a, b}$ Andrea Tura ${ }^{c}$ Carsten Thilo Herz ${ }^{d}$ Astrid Feder ${ }^{a, b}$ \\ Eva-Christina Krzizek ${ }^{a}$ b Verena Parzer $^{a} \quad$ Giovanni Pacini $^{c} \quad$ Bernhard Ludvik $^{a}$ b

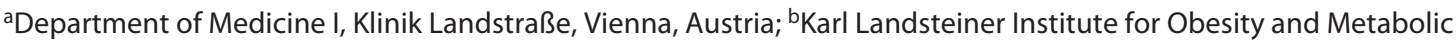

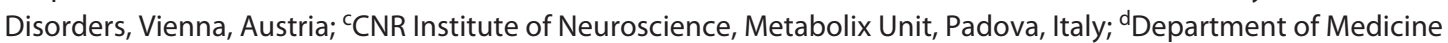 \\ III, Division for Nephrology and Dialysis, Medical University Vienna, Vienna, Austria
}

\section{Keywords}

Morbid obesity · Bariatric surgery · Cortisol excretion

\begin{abstract}
Introduction: Cortisol is involved in the regulation of gluconeogenesis and glucose utilization. In morbid obesity (MO), the association of cortisol excretion with metabolic parameters is not well-characterized. In our study, we evaluated cortisol excretion in nondiabetic subjects with $\mathrm{MO}$ and its effect on glucose metabolism. Methods: We included 1,249 nondiabetic patients with MO $(79.8 \%$ females, mean BMI $44.9 \pm 6.5 \mathrm{~kg} / \mathrm{m}^{2}$, mean age $38 \pm 11$ years). Anthropometric data and cardiovascular risk factors were assessed, and an oral glucose tolerance test for calculation of insulin resistance was performed. Cortisol excretion was assessed on 2 consecutive days (24 h urine specimens). Results: Regarding cortisol excretion, patients were divided into 3 tertiles (urinary cortisol $\leq 51.6,>51.6$ and $<117.6$, and $\geq 117.6 \mu \mathrm{g} / 24 \mathrm{~h}$, respectively). Patients in the highest tertile were younger $(p=0.003)$, more obese (BMI: $p=0.040)$, had lower diastolic blood pressure ([DBP]; $p=0.012)$, lower total $(p=0.032)$ and LDL cholesterol $(p=0.021)$, fasting $(p=0.049)$ and 2 -h glycemia $(p=0.028), 2-h$ insulinemia $(p=0.020)$, and $\mathrm{HbA} 1 \mathrm{c}(p<$
\end{abstract}

$0.001)$, and a higher estimated glomerular filtration rate (eGFR) $(p<0.001)$. The glucose $(p<0.001)$ and insulin $(p=$ 0.011 ) area under the curve (AUC) were also lower. Urinary cortisol excretion adjusted for age, sex, and eGFR was positively correlated with body weight $(\mathrm{BW}$, beta $=0.076, p=$ 0.004 ) and overall glucose tolerance (oral disposition index, beta $=0.090, p=0.011$ ), and negatively with $\mathrm{HbA} 1 \mathrm{c}$ (beta $=$ $-0.179, p<0.001)$, 2-h glycemia (beta $=-0.075, p=0.032$ ), AUC glucose (beta $=-0.103, p=0.002)$, and DBP (beta $=$ $-0.139, p<0.001)$. HbA1c, BW, and DBP remained significant after multivariable analysis. Discussion/Conclusion: Despite being more obese, patients with higher cortisol excretion have a more favorable metabolic profile. These results deserve further attention regarding the respective mechanisms.

(c) 2021 The Author(s) Published by S. Karger AG, Basel

\section{Introduction}

Increased cortisol levels are considered a consequence of obesity as well as a promoter of insulin resistance and increased hepatic gluconeogenesis, either when elevated by internal overproduction such as with Cushing's dis-
(C) 2021 The Author(s)

Published by S. Karger AG, Basel

This is an Open Access article licensed under the Creative Commons Attribution-NonCommercial-4.0 International License (CC BY-NC) (http://www.karger.com/Services/OpenAccessLicense), applicable to the online version of the article only. Usage and distribution for commercial purposes requires written permission.
Correspondence to:

Johanna Maria Brix, johanna.brix@ wienkav.at 
ease or following exogenous administration [1]. In that respect, the reduction of GLUT4 translocation to the cell surface is considered the responsible mechanism [2]. Insulin resistance induces a compensatory increase in betacell mass and eventually beta-cell failure. In vivo studies demonstrated an increase in the percentage of beta cells with proliferative activity following glucocorticoid administration, most likely as an indirect effect due to insulin resistance $[3,4]$. However, the direct effects of cortisol on the beta cell are not well-understood. An in vitro study in glucose-activated rat beta cells shows almost duplication in beta-cell mass after stimulation by hydrocortisone and methylprednisolone [5]. After transplantation of this amplified beta-cell mass in diabetic mice, these beta cells were able to normalize hyperglycemia over a follow-up period of 6 weeks [5]. In contrast, inhibitory effects or even no effects of glucocorticoids on glucose-stimulated insulin secretion have been shown in other in vitro studies $[6,7]$.

Likewise, corticosteroids play a major role in many aspects of adipose tissue biology. A crucial factor of local glucocorticoid action seems to be the expression of the enzyme 11 beta-hydroxysteroid dehydrogenase $(11 \beta-H S D)$ [8]. Two isoforms of $11 \beta-H S D$ exist; $11 \beta$-HSD1 converts inactive cortisone to active cortisol and is expressed in many tissues, such as the liver, adipose tissue, and central nervous system, as well as in skeletal and smooth muscle, fibroblasts, and immune cells [9-11]. Many studies have shown an increased expression of $11 \beta$-HSD1 in adipose tissue in obesity [11]. On contrary, $11 \beta$-HSD2 catalyzes the inactivation of cortisol to cortisone [10]. The role of $11 \beta$-HSD1 in adipose tissue seems to be not fully clear. A long time ago, an in vitro study showed that glucocorticoids exert an antiproliferative effect on preadipocytes, modulated by $11 \beta$-HSD1, as well as a clear stimulation of adipose conversion in the presence of insulin and high concentrations of cortisol levels [12]. Interestingly, in vitro studies show that in the presence of insulin, the addition of dexamethasone does not alter the expression of genes related to insulin action and triglyceride storage [13]. In monozygotic twins, an overexpression of $11 \beta$-HSD1 was associated with obesity [14]. It is therefore intriguing to claim $11 \beta-\mathrm{HSD} 1$ as a major contributor to obesity. In contrast, a study investigating omental and subcutaneous fat biopsies in obese women could not show an overexpression of $11 \beta-H S D 1$ [15].

However, almost all data in the literature are related to the impact of high, supraphysiologic glucocorticoid concentrations on glucose homeostasis and are mostly obtained by in vitro studies. For the present study, we hy- pothesized that cortisol excretion, as a parameter of its respective secretion, is associated with the metabolic profile, also within the physiologic range of endogenous production. Therefore, we investigated the relationship of cortisol excretion and several parameters of glucose metabolism in nondiabetic subjects with morbid obesity (MO). The novel aspects of this study would include the large number of subjects investigated with a broad range of metabolic characteristics as well as the comprehensive evaluation of parameters of glucose metabolism.

\section{Materials/Subjects and Methods}

\section{Study Population}

The study was approved by the Institutional Ethics Committee and complies with the Declaration of Helsinki, including current revisions and the good clinical practice guidelines. Subject participation and evaluation protocols were approved by the Institutional Ethics Committee of the city of Vienna (EK 19-077-VK). All subjects gave written informed consent before the study.

\section{Study Design}

We included 1,249 patients aged 18-60 years and BMI $>35 \mathrm{~kg} /$ $\mathrm{m}^{2}$, in a cross-sectional design $(79.8 \%$ females, mean BMI $44.9 \pm$ $6.5 \mathrm{~kg} / \mathrm{m}^{2}$, mean age $38 \pm 11$ years). Patients were systematically referred to a multidisciplinary team for medical, psychological, nutritional, and surgical treatment at the outpatient unit for $\mathrm{MO}$ of Klinik Landstraße, Vienna. All patients with type 2 diabetes either preknown or detected by an oral glucose tolerance test (oGTT) - were excluded from this study $(n=193)$. In addition, all patients with severe renal or liver disease were excluded $(n=17)$, as well as all patients on systemic oral therapy with glucocorticoids $(n=9)$.

\section{Analyses}

Demographic and clinical characteristics of all study participants are shown in Table 1. Peripheral blood samples were collected from all patients for determination of basic laboratory characteristics. All patients underwent a 75-g oGTT (venous blood samples taken at 0,60 , and $120 \mathrm{~min}$ ) for determination of glucose tolerance and insulin resistance/sensitivity. Basal serum cortisol, renal, and lipid parameters were assessed. All patients collected 24-h urine specimen on 2 consecutive days for determination of cortisol excretion. In case of urinary cortisol excretion above the normal limit, an overnight dexamethasone suppression test to exclude Cushing's syndrome was performed. Patients were advised not to collect urine during an infection.

\section{Measurement of Standard Laboratory Parameters}

Venous blood was taken after an overnight fast for measurement of biochemical and inflammatory factors. Blood glucose, cholesterol, HDL cholesterol, and triglycerides were measured by enzymatic in vitro tests (Roche Diagnostics GmbH, Graz, Austria); the intra-- and interassay coefficients of variation were $1.1 \%$ and $2.9 \%, 0.8 \%$ and $1.7 \%, 1.3 \%$ and $2.6 \%$, and $1.5 \%$ and $1.8 \%$, respectively. Glycosylated hemoglobin was measured by high-performance liquid chromatography (Diamat; Bio-Rad, Hercules, CA, 
Table 1. Baseline characteristics of all patients grouped $(n=1,030)$

Age, years

Weight, kg

BMI, $\mathrm{kg} / \mathrm{m}^{2}$

Body surface area, $\mathrm{m}^{2}$

Waist circumference, $\mathrm{cm}$

Cortisol, $\mathrm{nmol} / \mathrm{L}$

Urinary cortisol, $\mu \mathrm{g} / 24 \mathrm{~h}$

Systolic blood pressure, $\mathrm{mm} \mathrm{Hg}$

Diastolic blood pressure, $\mathrm{mm} \mathrm{Hg}$

Creatinine, $\mu \mathrm{mol} / \mathrm{L}$

eGFR, $\mathrm{mL} / \mathrm{min}^{-1}$

Glucose fasting, $\mathrm{mmol} / \mathrm{L}$

Glucose 1-h postprandial, $\mathrm{mmol} / \mathrm{L}$

Glucose 2-h postprandial, $\mathrm{mmol} / \mathrm{L}$

$\mathrm{HbAlc}, \mathrm{mmol} / \mathrm{mol}$

Insulin fasting, $\mathrm{pmol} / \mathrm{L}$

Insulin 1-h postprandial, $\mathrm{pmol} / \mathrm{L}$

Insulin 2-h postprandial, $\mathrm{pmol} / \mathrm{L}$

HOMA-IR

Cholesterol, $\mathrm{mmol} / \mathrm{L}$

HDL cholesterol, $\mathrm{mmol} / \mathrm{L}$

LDL cholesterol, $\mathrm{mmol} / \mathrm{L}$

Triglycerides, $\mathrm{mmol} / \mathrm{L}$

Data are depicted in mean \pm SD or median (25th-75th percentile), as appropriate. eGFR, estimated glomerular filtration rate.

USA). For quantification of insulin concentrations, an ELISA system was used (Enzymuntest Insulin, ES 600; Roche Corporation, Mannheim, Germany), for which the intra-- and interassay coefficients of variation were $3.5 \%$ and $5.6 \%$, respectively. Basal cortisol in the serum was measured by electrochemiluminescence immunoassay. Urinary cortisol was measured by a chemiluminescence immunoassay (ADVIA Centaur; Siemens Healthcare Diagnostics, Tarrytown, NY, USA).

\section{Calculation and Statistics}

Glucose and insulin values were used to model insulin resistance, insulin sensitivity, and beta-cell function. Insulin resistance and sensitivity at fasting were assessed by HOMA-IR and QUICKI, respectively $[16,17]$. Insulin sensitivity during the oGTT was assessed by the Matsuda index [18], OGIS [19], and PREDIM [20]. Beta-cell function was assessed at fasting by HOMA-beta [16]. During the oGTT, beta-cell function was assessed by the insulinogenic index and by the ratio of insulin to glucose area under the curve (AUC), both total and suprabasal [21, 22]. We also calculated the oral disposition index (ISSI-2) for an overall assessment of glucose tolerance [23]. In all patients, the mean urinary cortisol concentrations of $224 \mathrm{~h}$ samples were calculated. The estimated glomerular filtration rate (eGFR) was calculated by using the Corcoran-Salazar formula as this formula was specially derived for obese patients [24]. Data are presented as mean \pm SD or as median (25th-75th percentile) in case of nonnormal distribution. If appropriate, the parameters were logarithmized to gain a normal distribution. Differences between patients were analyzed by Student's paired, unpaired $t$ test or by the Mann-Whitney $\mathrm{U}$ test, the Wilcoxon or Kruskal-Wallis test, as appropriate. Data were tested for association within each other by univariate (Spearman) and multivariable regression analysis. For the multivariable regression analysis, the nonnormally distributed parameters were logarithmically transformed. An alpha level of $p<0.05$ (2-tailed) was considered statistically significant. Statistical analyses were performed with SPSS 22.0 (IBM Corporation, Armonk, NY, USA).

\section{Results}

A total of 1,249 patients were included in our study; however, 219 patients had to be excluded due to preexisting or newly diagnosed diabetes mellitus by oGTT or other mentioned exclusion criteria. Finally, 1,030 patients took part in this study. The median 24-h urinary cortisol excretion in the whole cohort was $85.2(40.9,135.7) \mu \mathrm{g} / 24$ h. Baseline characteristics of all patients are depicted in Table 1.

To distinguish the differences between patients with higher urinary cortisol and patients with lower urinary cortisol, patients were stratified into 3 groups according to urinary cortisol excretion. The tertiles were urinary cortisol $\leq 51.6 \mu \mathrm{g} / 24 \mathrm{~h} ;>51.6$ and $<117.6 \mu \mathrm{g} / 24 \mathrm{~h} ; \geq 117.6$ $\mu \mathrm{g} / 24 \mathrm{~h}$. Patients in the highest tertile were significantly younger $(p=0.003)$, more obese (body weight (BW) $[p<$ $0.001]$, BMI $[p=0.040])$, exhibited lower diastolic blood pressure (DBP) $(p=0.012)$, higher eGFR $(p<0.001)$, lower total cholesterol $(p=0.032)$, and lower LDL cholesterol $(p=0.021)$ compared to patients in the lowest tertile. We did not find any differences in basal serum cortisol levels or creatinine levels. All differences in all baseline characteristics according to cortisol tertiles are shown in Table 2.

\section{Glucose and Insulin Relationship}

Patients in the highest tertile of urinary cortisol excretion show a more favorable glucose metabolism compared to patients in the lowest cortisol tertile, such as lower fasting $(p=0.049)$ and $2 \mathrm{~h}(p=0.028)$ postprandial glucose levels, $2 \mathrm{~h}$ postprandial insulin levels $(p=0.020)$ and HbAlc levels $(p<0.001)$. In addition, the AUC of glucose and the AUC of insulin are significantly lower in patients in the highest tertile compared with those in the lowest tertile $(p<0.001$ and $p=0.011$, respectively; see Table 3$)$. In addition, there was also a trend regarding lower $1 \mathrm{~h}$ postprandial glucose levels $(p=0.070)$.

In terms of metabolic parameters, although patients in the highest cortisol tertile had a more favorable glucose metabolism, we could not find any difference in insulin 
Table 2. Baseline characteristics according to cortisol tertiles in patients without diabetes

\begin{tabular}{|c|c|c|c|c|c|}
\hline & \multicolumn{5}{|c|}{ Cortisol excretion } \\
\hline & $\begin{array}{l}\leq 51.6 \mu \mathrm{g} / 24 \mathrm{~h} \\
(n=343)\end{array}$ & $\begin{array}{l}>51.6 \text { and }<117.6 \mu \mathrm{g} / 24 \mathrm{~h} \\
(n=344)\end{array}$ & $\begin{array}{l}\geq 117.6 \mu \mathrm{g} / 24 \mathrm{~h} \\
(n=343)\end{array}$ & $\begin{array}{l}p \text { value } \\
\text { ANOVA }^{\#}\end{array}$ & $\begin{array}{l}p \text { value first } \\
\text { versus third }\end{array}$ \\
\hline Age, years & $39 \pm 12$ & $38 \pm 11$ & $37 \pm 12$ & 0.095 & 0.003 \\
\hline Weight, kg & $125 \pm 22$ & $127 \pm 22$ & $133 \pm 24$ & $<0.001$ & $<0.001$ \\
\hline BMI, $\mathrm{kg} / \mathrm{m}^{2}$ & $44.5 \pm 7.0$ & $44.6 \pm 6.1$ & $45.6 \pm 6.5$ & 0.029 & 0.040 \\
\hline Systolic blood pressure, $\mathrm{mm} \mathrm{Hg}$ & $140 \pm 16$ & $142 \pm 17$ & $141 \pm 17$ & 0.770 & 0.115 \\
\hline Diastolic blood pressure, $\mathrm{mm} \mathrm{Hg}$ & $92 \pm 11$ & $91 \pm 12$ & $89 \pm 11$ & $<0.001$ & 0.012 \\
\hline Cortisol, $\mathrm{nmol} / \mathrm{L}$ & $444 \pm 196$ & $450 \pm 201$ & $450 \pm 315$ & 0.856 & 0.639 \\
\hline Creatinine, $\mu \mathrm{mol} / \mathrm{L}$ & $61 \pm 15$ & $61 \pm 15$ & $61 \pm 15$ & 0.693 & 0.934 \\
\hline $\mathrm{eGFR}, \mathrm{mL} / \mathrm{min}^{-1}$ & $124 \pm 31$ & $129 \pm 30$ & $135 \pm 35$ & $<0.001$ & $<0.001$ \\
\hline Cholesterol, mmol/L & $5.2 \pm 1.0$ & $5.1 \pm 1.0$ & $5.1 \pm 0.9$ & 0.107 & 0.032 \\
\hline
\end{tabular}

Data are depicted in mean \pm SD or median (25th-75th percentile), as appropriate. eGFR, estimated glomerular filtration rate. ${ }^{\#}$ For nonparametric distributed values, the Kruskal-Wallis $\mathrm{H}$ test was used. ${ }^{\S}$ For nonparametric distributed values, the Mann-Whitney $\mathrm{U}$ test was used.

resistance or insulin sensitivity in basal parameters such as HOMA-IR ( $p=0.883)$ and QUICKI $(p=0.681)$. Regarding the dynamic parameters, we did neither find a difference in the Matsuda index $(p=0.656)$, PREDIM $(p=0.456)$, or insulinogenic index $(p=0.827)$. However, regarding beta-cell function, we found a trend to improvement in patients in the highest cortisol tertile, indicated by a higher HOMA-beta $(p=0.059)$ - as a basal beta-cell function model. On the other hand, we did not find any difference in the ISSI- $2(p=0.155)$, being an index, which depicts beta-cell function adjusted to insulin sensitivity in a dynamic fashion, in the AUC insulin/AUC glucose ratio $(p=0.684)$, or in the $\triangle \mathrm{AUC}$ insulin/ $\triangle \mathrm{AUC}$ glucose ratio, that is, its suprabasal component $(p=$ 0.823). All detailed results are shown in Table 3.

\section{Correlation Analysis}

To identify associations with urinary cortisol, we performed a univariate correlation analysis where we included all baseline characteristics. We found age $(r=-0.087$; $p=0.011)$, DBP $(r=-0.134 ; p<0.001)$, weight $(r=0.178$; $p<0.001)$, BMI $(r=0.094 ; p=0.008)$, fasting glucose $(r=$ $-0.088 ; p=0.006), 1$-h postprandial glucose $(r=-0.074$; $p=0.023), 2-\mathrm{h}$ postprandial glucose $(r=-0.091 ; p=$ $0.005), \mathrm{HbA1c}(r=-0.172 ; p<0.001)$, AUC glucose $(r=$ $-0.202 ; p<0.001)$, HOMA-beta $(r=0.074 ; p=0.025)$,
ISSI-2 $(r=0.088 ; p=0.008)$, and eGFR $(r=0.135 ; p<$ $0.001)$ correlated with urinary cortisol levels. In a next step, we adjusted these associates for age and sex (see Table 4; model 2) and additionally for eGFR (see Table 4; model 3). After the final adjustment, weight $(r=0.076$; $p=0.004)$, DBP $(r=-0.139 ; p<0.001)$, blood glucose $2-\mathrm{h}$ postprandial $(r=-0.075 ; p=0.032), \mathrm{HbAlc}(r=-0.179$; $p<0.001)$, AUC glucose $(r=-0.103 ; p=0.002)$, and ISSI$2(r=0.090 ; p=0.011)$ still remained significantly associated (Fig. 1).

Additionally, we performed a multiple backward stepwise regression analysis while retaining age, sex, and eGFR as confounders to identify the most probable predictors for urinary cortisol values. We included all variables which were associated in the univariate model, except for 2-h and 1-h postprandial glucose, as they are included in the calculations of AUC glucose and the ISSI-2 index, respectively. The ISSI- 2 index interacts strongly with AUC glucose; therefore, we chose the variable that was strongly associated in univariate analysis. The final model consisted of HbA1c (beta $=-0.191 ; p<0.001$ ), weight (beta $=0.150 ; p<0.001)$, and DBP (beta $=-0.133$; $p<0.001)$ indicating that a lower HbAlc, lower DBP, and higher weight are the most possible predictors for higher urinary cortisol levels. 
Table 3. Glucose metabolism and modeling according to cortisol tertiles in patients without diabetes

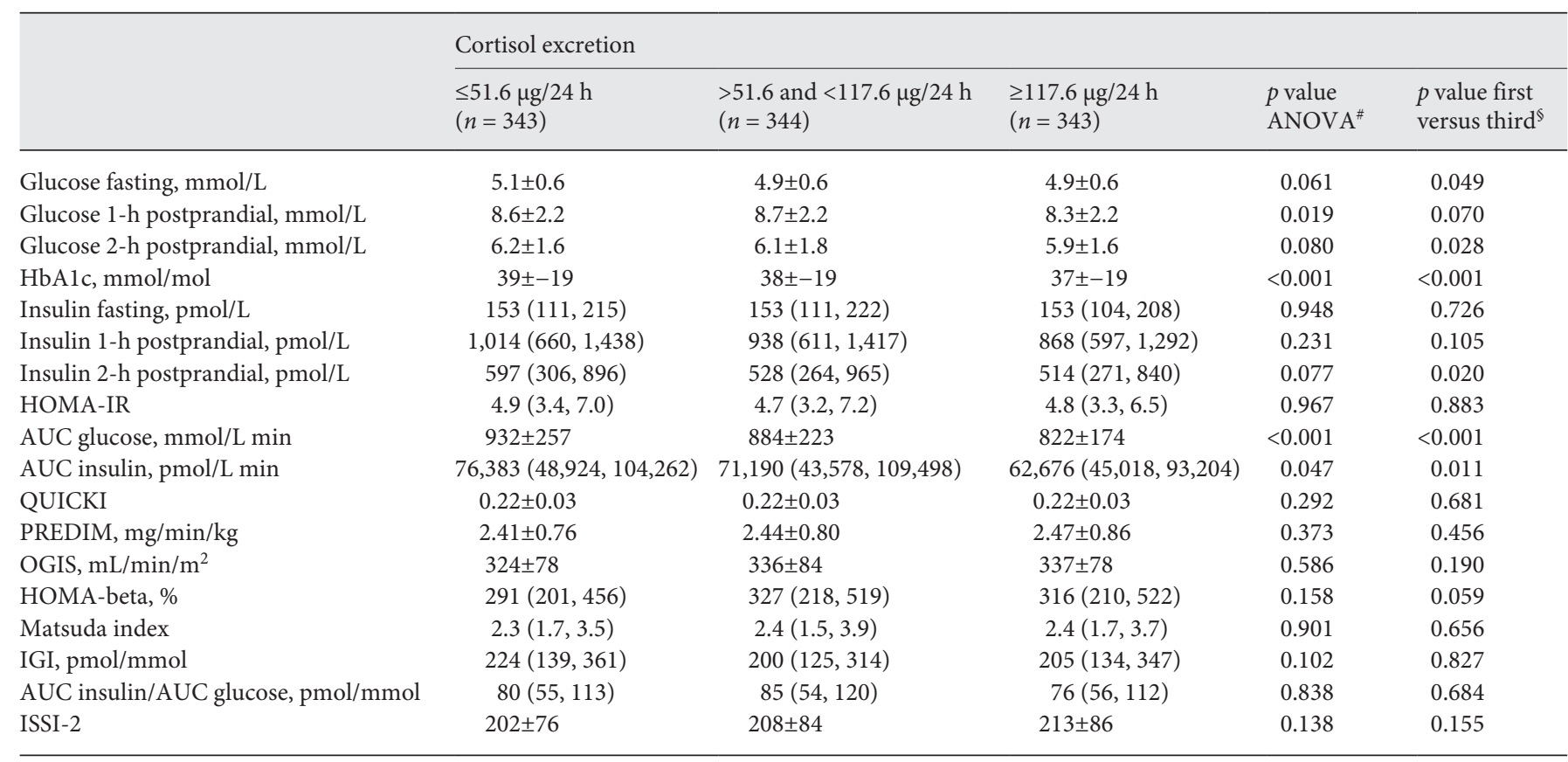

Data are depicted in mean \pm SD or median (25th-75th percentile), as appropriate. AUC, area under the curve; PREDIM, predictor of clamp-based insulin sensitivity; IGI, insulinogenic index; ISSI-2, oral disposition index. ${ }^{\#}$ For nonparametric distributed values, the Kruskal-Wallis $\mathrm{H}$ test was used. ${ }^{\S}$ For nonparametric distributed values, the Mann-Whitney U test was used.

Table 4. Univariate correlation analysis of variables associated with urinary cortisol levels in patients without diabetes

\begin{tabular}{|c|c|c|c|c|c|c|}
\hline & \multicolumn{2}{|c|}{ Model 1 (unadjusted) } & \multicolumn{2}{|c|}{$\begin{array}{l}\text { Model } 2 \text { (adjusted } \\
\text { for age and sex) }\end{array}$} & \multicolumn{2}{|c|}{$\begin{array}{l}\text { Model } 3 \text { (adjusted for } \\
\text { age, sex, and eGFR) }\end{array}$} \\
\hline & $r$ & $p$ value & beta & $p$ value & beta & $p$ value \\
\hline Age, years & -0.087 & 0.011 & & & & \\
\hline Weight & 0.178 & $<0.001$ & 0.110 & $<0.001$ & 0.076 & 0.004 \\
\hline BMI & 0.094 & 0.008 & 0.071 & 0.052 & 0.036 & 0.263 \\
\hline Blood pressure, diastolic & -0.134 & $<0.001$ & -0.133 & $<0.001$ & -0.139 & $<0.001$ \\
\hline Blood glucose, fasting & -0.088 & 0.006 & -0.041 & 0.216 & -0.050 & 0.134 \\
\hline Blood glucose, 1-h postprandial & -0.074 & 0.023 & -0.041 & 0.223 & -0.047 & 0.162 \\
\hline Blood glucose, 2-h postprandial & -0.091 & 0.005 & -0.078 & 0.024 & -0.075 & 0.032 \\
\hline HbAlc & -0.172 & $<0.001$ & -0.172 & $<0.001$ & -0.179 & $<0.001$ \\
\hline AUC glucose & -0.202 & $<0.001$ & -0.098 & 0.004 & -0.103 & 0.002 \\
\hline HOMA-beta & 0.074 & 0.025 & 0.023 & 0.509 & 0.021 & 0.545 \\
\hline ISSI- 2 & 0.088 & 0.008 & 0.085 & 0.016 & 0.090 & 0.011 \\
\hline eGFR & 0.135 & $<0.001$ & 0.062 & 0.032 & & \\
\hline
\end{tabular}

AUC, area under the curve; eGFR, estimated glomerular filtration rate; ISSI-2, oral disposition index. 

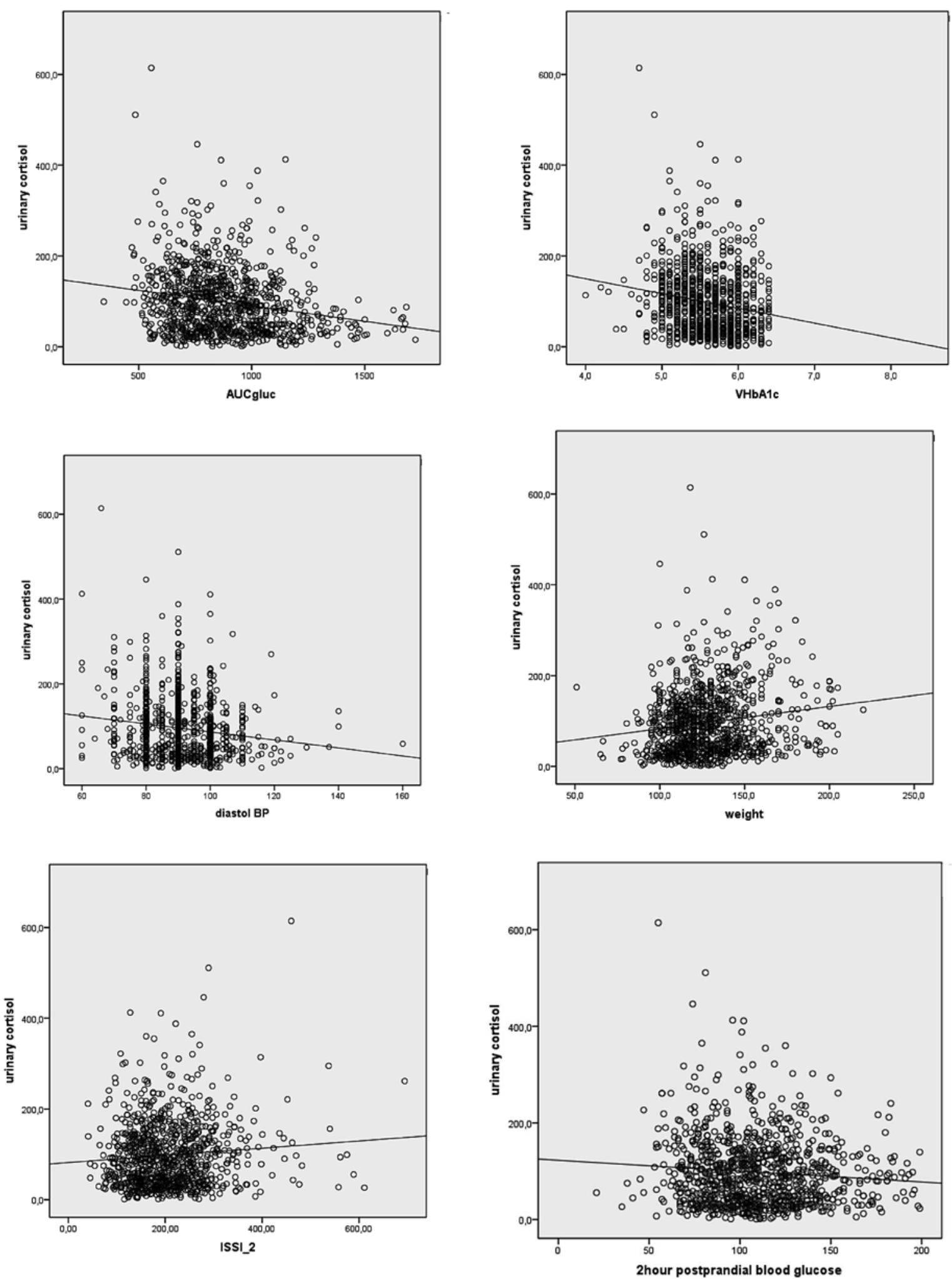

Fig. 1. Univariate correlation of parameters with urinary cortisol excretion after adjustment for estimated glomerular filtration rate graphically depicted. 


\section{Discussion}

We were able to demonstrate in a large cohort of patients with MO that urinary cortisol excretion adjusted for eGFR is positively correlated with BW and overall glucose tolerance, and negatively with $\mathrm{HbA1c}$, post-challenge glucose concentration, and $\mathrm{DBP}$. $\mathrm{HbAlc}, \mathrm{BW}$, and DBP remained significantly associated with cortisol excretion in a multivariable analysis. These findings indicate a more favorable metabolic profile in obese subjects with higher cortisol excretion, which is also confirmed, when data for subjects in the lowest and highest tertiles of cortisol excretion are analyzed.

Cortisol production and secretion are increased in obesity $[25,26]$ and lead to enhanced urinary free cortisol levels, as also shown in women with abdominal body fat distribution $[27,28]$. Increased urinary cortisol excretion in obesity is regarded as a consequence of overactivity of the hypothalamic-pituitary-adrenal (HPA) axis [29, 30]. In that regard, we would expect a less favorable metabolic profile in our subjects with higher cortisol excretion, which has however not been confirmed. Indeed, subjects in the highest tertile of cortisol excretion exhibited advantageous glucose-related and metabolic parameters.

Effects of cortisol directly on the beta cell are still not well-understood. Indirect effects on beta-cell secretion due to cortisol-induced insulin resistance are difficult to separate from the direct effects of cortisol on the beta cell [31]. Transgenic mice with an increased glucocorticoid sensitivity restricted to their beta cells were generated by overexpressing the glucocorticoid receptor under the control of the insulin promoter [32]. Intravenous glucose tolerance tests showed that the glucocorticoid receptor transgenic mice had normal fasting and postabsorptive blood glucose levels but exhibited reduced glucose tolerance. Dexamethasone treatment on isolated beta cells leads to posttranslational degradation of GLUT2 and inhibition of insulin secretion in isolated pancreatic cells as well as suppression of the insulin gene expression [33, 34]. In these studies however, supraphysiological doses as well as synthetic dexamethasone have been employed. In our study, cortisol excretion was predominantly within the normal range. In those subjects with urinary cortisol excretion exceeding the upper normal range, a dexamethasone suppression test excluded hypercortisolemia.

The recent discovery of a mechanism by which glucocorticoids maintain beta-cell function in human and rodent beta cells through the engagement of parallel cAMP pathways has been described [35]. The authors demonstrated that at physiological levels, cortisol and their less active precursors 11-dehydrocorticosterone and cortisone suppress voltage-dependent $\mathrm{Ca}^{2+}$ channel function and $\mathrm{Ca}^{2+}$ fluxes in human and rodent beta cells. However, insulin secretion, maximal ATP/ADP response to glucose, and beta-cell identity were all unaltered. Further studies revealed an upregulation of parallel amplifying cAMP signals and an increase in the number of membrane-docked insulin secretory granules. Effects of 11-dehydrocorticosterone could be prevented by lipotoxicity and were associated with paracrine regulation of glucocorticoid activity because global deletion of $11 \beta-\mathrm{HSD}$ type 1 normalized $\mathrm{Ca}^{2+}$ and cAMP responses. The authors concluded that failure of this protective mechanism might contribute to diabetes in states of glucocorticoid excess, which are associated with frank dyslipidemia [35]. Our patients however were nondiabetic and presented with normal triglyceride levels. Thus, patients in the highest cortisol tertile with the same degree of insulin resistance as those in the lowest tertile exhibited a significantly better overall glucose metabolism, indicated by ISSI- 2 .

Another study supporting our data is an analysis of the Whitehall II study, where obese participants had significantly lower morning salivary cortisol levels than lean participants [36]. We did not measure salivary cortisol in our study; however, basal morning serum cortisol levels were not different between the respective groups.

DBP values were significantly lower in subjects with higher urinary cortisol excretion. The negative correlation of DBP and urinary cortisol levels was even part of the multivariable analysis for the prediction of urinary cortisol excretion. Our data are in line with a study on the association of cortisol/cortisone ratio and blood pressure in 43 men before and after weight loss [37]. Despite the much lower sample size, the authors could show a trend toward a negative correlation of basal serum cortisol and DBP in obese men $(r=-0.29 ; p=0.06)$ [37].

Increased cortisol secretion can also be linked to increased lean body mass [38]. Since the adrenal gland size is associated with the body surface area and BMI, urinary cortisol excretion should be corrected for the body surface area [39-41]. In our study population, cortisol excretion was positively associated with BW. The body surface area was higher in the highest cortisol excretion group but did not show a significant correlation. Along that line, correction of cortisol excretion rates for lean body mass revealed no difference in cortisol production rates between lean and severely obese subjects [42]. We did not measure lean body mass; however, our patients in the highest tertile of cortisol excretion were significantly younger and more obese, which could serve as an indirect 
marker of increased muscle mass. This in turn could explain the more favorable metabolic parameters in this cohort.

Hyperactivity of the HPA axis in obesity has been questioned by reports of subnormal 24-h mean plasma cortisol concentrations in obese adults [43]. This could indicate an increased cortisol metabolic clearance rate leading to a higher urinary cortisol secretion, as shown in obesity, and especially in obese women $[44,45]$. In our study, we could not detect any differences in basal morning cortisol levels between the groups, which however do not preclude differences in overall cortisol secretion. In that regard, the higher weight in subjects with increased urinary cortisol excretion could indicate a lower overall cortisol secretion rate with corresponding beneficial effects on metabolic parameters. This however remains speculative.

There are however additional factors to be considered as potential reasons for the somewhat surprising findings of our study. In women, it has been shown that inflammation of omental fat is increased which in turn is associated with decreased expression of lipogenic markers [46]. The inflammation could trigger a stimulation of the HPA axis and thus increase cortisol production. Since we have no data on body fat distribution, we cannot rule out any differences in the amount of omental fat associated with inflammation between the respective tertiles of our subjects. In addition, genetic variabilities in human adipose tissue can be considered relevant for differences in inflammation and glucose homeostasis [47].

Our study has some limitations such as the lack of a lean control group, assessment of body composition, and markers of cortisol production and urinary excretion rates. In addition, as with most studies in MO, almost $80 \%$ of our study participants are women. In our study, we have no information about activity levels or duration and quality of sleep as potentially cofounding parameters of cortisol excretion and the response to the oGTT. Regarding activity levels however, we assume it will most likely be generally low in morbidly obese subjects. The strengths of our study are the large sample size, a wellcharacterized patient cohort with exclusion of diabetic patients with impaired beta-cell function by oGTT, and repeated assessment of cortisol excretion. Moreover, we exploited different methods to assess metabolic parameters to exclude any possible bias due to the specific evaluation technique. All different ways of measuring insulin sensitivity and secretion yielded indeed the same conclusions.
In conclusion, our data in a large cohort of nondiabetic patients with MO surprisingly revealed a positive association of cortisol excretion and parameters of glucose metabolism and cardiovascular risk factors. The mechanisms for these findings need further studies to better characterize cortisol metabolism in obesity and its consequences on glucose metabolism.

\section{Statement of Ethics}

Our research complies with the guidelines for human studies and should include evidence that the research was conducted ethically in accordance with the World Medical Association Declaration of Helsinki. Subject participation and evaluation protocols were approved by the Institutional Ethics Committee of the city of Vienna (EK 19-077-VK). All study participants provided their written informed consent to participate in the study.

\section{Conflict of Interest Statement}

The authors have no conflicts of interest to declare.

\section{Funding Sources}

No funding was needed for this work.

\section{Author Contributions}

All authors provided substantial contribution to the design and implementation of this study and to the generation of the manuscript. The contributions of each author are as follows: J.M. Brix and B. Ludvik conceived the study design. J.M. Brix, E.-C. Krzizek, and A. Feder acquired the data. J.M. Brix, A. Tura, C.T. Herz, and G. Pacini analyzed the data and interpreted the findings. J.M. Brix, A. Tura, A. Feder, E.-C. Krzizek, V. Parzer, and B. Ludvik drafted the manuscript. J.M. Brix, A. Tura, C.T. Herz, A. Feder, E.-C. Krzizek, V. Parzer, G. Pacini, and B. Ludvik provided critical revisions and final approval of the version submitted.

\section{Data Availability Statement}

The data that support the findings of this study are not publicly available due to containing information that could compromise the privacy of research participants but are available from J.M. Brix. 


\section{References}

1 Andrews RC, Walker BR. Glucocorticoids and insulin resistance: old hormones, new targets. Cli Sci. 1999;96(5):513-23.

2 Weinstein SP, Wilson CM, Pritsker A, Cushman SW. Dexamethasone inhibits insulinstimulated recruitment of GLUT4 to the cell surface in rat skeletal muscle. Metabolism. 1998 Jan;47(1):3-6.

3 Like AA, Chick WL. Pancreatic beta cell replication induced by glucocorticoids in subhuman primates. Am J Pathol. 1974 May;75(2): 329-48.

4 Rafacho A, Cestari TM, Taboga SR, Boschero AC, Bosqueiro JR. High doses of dexamethasone induce increased beta-cell proliferation in pancreatic rat islets. Am J Physiol Endocrinol Metab. 2009 Apr;296(4):E681-9.

5 Assefa Z, Akbib S, Lavens A, Stangé G, Ling $\mathrm{Z}$, Hellemans KH, et al. Direct effect of glucocorticoids on glucose-activated adult rat $\beta$-cells increases their cell number and their functional mass for transplantation. Am J Physiol Endocrinol Metab. 2016 Oct 1;311(4): E698-705.

6 Lambillotte C, Gilon P, Henquin JC. Direct glucocorticoid inhibition of insulin secretion. An in vitro study of dexamethasone effects in mouse islets. J Clin Invest. 1997;99(3):414-23.

7 Swali A, Walker EA, Lavery GG, Tomlinson JW, Stewart PM. 11Beta-hydroxysteroid dehydrogenase type 1 regulates insulin and glucagon secretion in pancreatic islets. Diabetologia. 2008;51(11):2003-11.

8 Anagnostis $\mathrm{P}$, Athyros VG, Tziomalos K, Karagiannis A, Mikhailidis DP. Clinical review: the pathogenetic role of cortisol in the metabolic syndrome: a hypothesis. J Clin Endocrinol Metab. 2009 Aug;94(8):2692-701.

9 Anagnostis P, Katsiki N, Adamidou F, Athyros VG, Karagiannis A, Kita M, et al. 11betahydroxysteroid dehydrogenase type 1 inhibitors: novel agents for the treatment of metabolic syndrome and obesity-related disorders? Metabolism. 2013 Jan;62(1):21-33.

10 Cooper MS, Stewart PM. 11beta-hydroxysteroid dehydrogenase type 1 and its role in the hypothalamus-pituitary-adrenal axis, metabolic syndrome, and inflammation. J Clin Endocrinol Metab. 2009;94(12):4645-54.

11 Tomlinson JW, Walker EA, Bujalska IJ, Draper N, Lavery GG, Cooper MS, et al. 11betahydroxysteroid dehydrogenase type 1: a tissue-specific regulator of glucocorticoid response. Endocr Rev. 2004 Oct;25(5):831-66.

12 Grégoire F, Genart C, Hauser N, Remacle C. Glucocorticoids induce a drastic inhibition of proliferation and stimulate differentiation of adult rat fat cell precursors. Exp Cell Res. 1991 Oct;196(2):270-8.

13 Lee MJ, Gong DW, Burkey BF, Fried SK. Pathways regulated by glucocorticoids in omental and subcutaneous human adipose tissues: a microarray study. Am J Physiol Endocrinol Metab. 2011;300(3):E571-80.
14 Kannisto K, Pietiläinen $\mathrm{KH}$, Ehrenborg E, Rissanen A, Kaprio J, Hamsten A, et al. Overexpression of 11beta-hydroxysteroid dehydrogenase-1 in adipose tissue is associated with acquired obesity and features of insulin resistance: studies in young adult monozygotic twins. J Clin Endocrinol Metab. 2004 Sep; 89(9):4414-21.

15 Tomlinson JW, Sinha B, Bujalska I, Hewison M, Stewart PM. Expression of 11beta-hydroxysteroid dehydrogenase type 1 in adipose tissue is not increased in human obesity. J Clin Endocrinol Metab. 2002 Dec;87(12): 5630-5.

16 Matthews DR, Hosker JP, Rudenski AS, Naylor BA, Treacher DF, Turner RC. Homeostasis model assessment: insulin resistance and b-cell function from fasting plasma glucose and insulin concentrations in man. Diabetologia. 1985;28:412-9.

17 Katz A, Nambi SS, Mather K, Baron AD, Follmann DA, Sullivan G, et al. Quantitative insulin sensitivity check index: a simple, accurate method for assessing insulin sensitivity in humans. J Clin Endocrinol Metab. 2000; 85(7):2402-10.

18 Matsuda M, DeFronzo RA. Insulin sensitivity indices obtained from oral glucose tolerance testing. Comparison with the euglycemic insulin clamp. Diabetes Care. 1999;22:1462-70.

19 Mari A, Pacini G, Murphy E, Ludvik B, Nolan JJ. A model-based method for assessing insulin sensitivity from the oral glucose tolerance test. Diabetes Care. 2001;24(3):539-48.

20 Tura A, Chemello G, Szendroedi J, Göbl C, Færch K, Vrbíková J, et al. Prediction of clamp-derived insulin sensitivity from the oral glucose insulin sensitivity index. Diabetologia. 2018 May;61(5):1135-41.

21 Phillips DI, Clark PM, Hales CN, Osmond C. Understanding oral glucose tolerance: comparison of glucose or insulin measurements during the oral glucose tolerance test with specific measurements of insulin resistance and insulin secretion. Diabet Med. 1994; 11(3):286-92.

22 Tura A, Kautzky-Willer A, Pacini G. Insulinogenic indices from insulin and C-peptide: comparison of beta-cell function from OGTT and IVGTT. Diabetes Res Clin Pract. 2006 Jun;72(3):298-301.

23 Retnakaran R, Qi Y, Goran MI, Hamilton JK. Evaluation of proposed oral disposition index measures in relation to the actual disposition index. Diabet Med. 2009 Dec;26(12):1198203.

24 Salazar DE, Corcoran GB. Predicting creatinine clearance and renal drug clearance in obese patients from estimated fat-free body mass. Am J Med. 1988 Jun;84(6):1053-60.

25 Dunkelman SS, Fairhurst B, Plager J, Waterhouse C. Cortisol metabolism in obesity. J Clin Endocrinol Metab. 1964;24:832-41.
26 Purnell JQ, Brandon DD, Isabelle LM, Loriaux DL, Samuels MH. Association of 24-hour cortisol production rates, cortisol-binding globulin, and plasma-free cortisol levels with body composition, leptin levels, and aging in adult men and women. J Clin Endocrinol Metab. 2004;89(1):281-7.

27 Mårin P, Darin N, Amemiya T, Andersson B, Jern S, Björntorp P. Cortisol secretion in relation to body fat distribution in obese premenopausal women. Metabolism. 1992; 41(8):882-6.

28 Pasquali R, Cantobelli S, Casimirri F, Capelli M, Bortoluzzi L, Flamia R, et al. The hypothalamic-pituitary-adrenal axis in obese women with different patterns of body fat distribution. J Clin Endocrinol Metab. 1993;77(2): 341-6.

29 Björntorp P, Holm G, Rosmond R. Hypothalamic arousal, insulin resistance and type 2 diabetes mellitus. Diabetes Med. 1999;16(5): 373-83.

30 Dimitriou T, Maser-Gluth C, Remer T. Adrenocortical activity in healthy children is associated with fat mass. Am J Clin Nutr. 2003; 77(3):731-6.

31 Kuo T, McQueen A, Chen TC, Wang JC. Regulation of glucose homeostasis by glucocorticoids. Adv Exp Med Biol. 2015;872:99-126.

32 Delaunay F, Khan A, Cintra A, Davani B, Ling ZC, Andersson A, et al. Pancreatic beta cells are important targets for the diabetogenic effects of glucocorticoids. J Clin Invest. 1997; 100(8):2094-8.

33 Gremlich S, Roduit R, Thorens B. Dexamethasone induces posttranslational degradation of GLUT2 and inhibition of insulin secretion in isolated pancreatic beta cells. Comparison with the effects of fatty acids. J Biol Chem. 1997;272(6):3216-22.

34 Goodman PA, Medina-Martinez O, Fernandez-Mejia C. Identification of the human insulin negative regulatory element as a negative glucocorticoid response element. Mol Cell Endocrinol. 1996;120(2):139-46.

35 Fine NHF, Doig CL, Elhassan YS, Vierra NC, Marchetti P, Bugliani M, et al. Glucocorticoids reprogram $\beta$-cell signaling to preserve insulin secretion. Diabetes. 2018 Feb;67(2): 278-90.

36 Kumari M, Chandola T, Brunner E, Kivimaki M. A nonlinear relationship of generalized and central obesity with diurnal cortisol secretion in the Whitehall II study. J Clin Endocrinol Metab. 2010 Sep;95(9):4415-23.

37 Byrd JB, Rothberg AE, Chomic R, Burant CF, Brook RD, Auchus RJ. Serum cortisol-to-cortisone ratio and blood pressure in severe obesity before and after weight loss. Cardiorenal Med. 2015 Dec;6(1):1-7.

38 Müssig K, Remer T, Maser-Gluth C. Brief review: glucocorticoid excretion in obesity. J Steroid Biochem Mol Biol. 2010;121(3-5): 589-93. 
39 Rubin RT, Phillips JJ. Adrenal gland volume determination by computed tomography and magnetic resonance imaging in normal subjects. Invest Radiol. 1991;26(5):465-9.

40 Ludescher B, Najib A, Baar S, Machann J, Schick F, Buchkremer G, et al. Increase of visceral fat and adrenal gland volume in women with depression: preliminary results of a morphometric MRI study. Int J Psychiatry Med. 2008;38(3):229-40.

41 Müssig K, Remer T, Haupt A, Gallwitz B, Fritsche A, Häring H-U, et al. $11 \beta$-hydroxysteroid dehydrogenase 2 activity is elevated in severe obesity and negatively associated with insulin sensitivity. Obesity. 2008;16(6):1256-60.
42 Prezio JA, Carreon G, Clerkin E, Meloni CR, Kyle LH, Canary JJ. Influence of body composition on adrenal function in obesity. J Clin Endocrinol Metab. 1964;24:481-5.

43 Jessop DS, Dallman MF, Fleming D, Lightman SL. Resistance to glucocorticoid feedback in obesity. J Clin Endocrinol Metab. 2001;86(9):4109-14.

44 Rask E, Walker BR, Söderberg S, Livingstone $\mathrm{DE}$, Eliasson M, Johnson O, et al. Tissue-specific changes in peripheral cortisol metabolism in obese women: increased adipose $11 \mathrm{be}-$ ta-hydroxysteroid dehydrogenase type 1 activity. J Clin Endocrinol Metab. 2002;87(7): $3330-6$.
45 Vierhapper H, Nowotny P, Waldhäusl W. Production rates of cortisol in obesity. Obes Res. 2004;12(9):1421-5.

46 Poulain-Godefroy O, Lecoeur C, Pattou F, Frühbeck G, Froguel P. Inflammation is associated with a decrease of lipogenic factors in omental fat in women. Am J Physiol Regul Integr Comp Physiol. 2008 Jul;295(1):R1-7.

47 Catalán V, Gómez-Ambrosi J, Rotellar F, Silva $\mathrm{C}$, Rodríguez A, Salvador J, et al. Validation of endogenous control genes in human adipose tissue: relevance to obesity and obesityassociated type 2 diabetes mellitus. Horm Metab Res. 2007 Jul;39(7):495-500. 